\title{
KAJIAN PUSAT SPIRITUAL DALAM KONTEKS JAWA
}

\author{
Karen Claudia ${ }^{1)}$, Rudy Trisno ${ }^{2)}$ \\ 1)Program Studi S1 Arsitektur, Fakultas Teknik, Univeritas Tarumanagara, christykarenruth@gmail.com \\ 2) Program Studi S1 Arsitektur, Fakultas Teknik, Universitas Tarumanagara, rudyt@ft.untar.ac.id
}

\begin{abstract}
Abstrak
Penganut spiritualitas memerlukan sebuah komunitas, oleh sebab itu, diajukan perancangan pusat spiritual untuk mewadahi kebutuhan spiritual bagi komunitas spiritual di Jakarta. Dalam perancangan pusat spiritualitas diperlukan elemen transenden dalam bangunan, maka digali tipologi sesuai konteks yang diterjemahkan ke dalam bangunan melalui komposisi dan teknik modern. Metode penilitian yang diperlukan untuk menimbulkan suasana spiritual adalah keseimbangan antara mass dan void, alam dan manusia, cahaya dan bayangan, serta ruang dan waktu. Sehingga dapat disimpulkan dan ditemukan bahwa kesatuan dalam dualitas adalah prinsip penting dalam proses perancangan arsitektur spiritual.
\end{abstract}

Kata kunci: arsitektur lokal; genius loci; kontekstual; lokalitas; rumah adat Jawa; spiritualitas

\begin{abstract}
Spiritual adherents now long for a community. In response to that, a design for a spiritual center is proposed to accommodate the spiritual needs of a spiritual community in Jakarta. Designing a spiritual center requires an element of the transcendent to be infused into the building. Modern composition and technology is used as a language to translate the typology appropriate to the context into an actual building. An insight on traditional Javanese architecture shows that harmony between mass and void, nature and man, light and shadow, and space and time is needed to synthesize spirituality in architecture. Therefore, the conclusion and finding is that unity between dualities is important in designing spiritual architecture.
\end{abstract}

Keywords: contextual; genius loci; local architecture; locality; traditional Javanese house

\section{PENDAHULUAN}

Lima hierarki kebutuhan yang dikemukakan Maslow terdiri dari kebutuhan fisiologis, keamanan, kasih sayang, harga diri, dan aktualisasi diri. Tingkat keenam di atas aktualitasi diri yang dapat dicapai ketika kelima kebutuhan sudah tercapai adalah transendensi (Maslow, 1970), yang dapat dicapai melalui spiritualitas. Seiring dengan perkembangan kebudayaan dan teknologi, kebutuhan dasar lebih mudah dicapai, hingga sekarang terdapat pergeseran tingkat kebutuhan dasar menjadi kebutuhan sosial, yang juga mudah dicapai melalui keberadaan internet dan media sosial. Sehingga kebutuhan spiritualitas semakin dekat menjadi kebutuhan penting. Pada saat ini, keperluan utama bagi penganut spiritualitas adalah untuk bertemu dengan sesamanya dan membentuk komunitas (Van Niekerk, 2018). Oleh sebab itu, diajukan perancangan pusat spiritual untuk mewadahi pertumbuhan spiritual bagi komunitas spiritual di Jakarta.

Dalam perancangan pusat spiritualitas diperlukan sebuah jiwa tempat atau genius loci yang digalih dari nilai kebudayaan setempat. Jakarta, sebagai ibukota Indonesia, telah kehilangan jejak kebudayaan dalam arsitekturnya. Skyline terlihat serupa dengan kota-kota lain, yaitu terdiri dari bangunan tinggi bergaya internasional. Maka dari itu, perlu diselidiki elemenelemen yang dapat menciptakan kesakralan dalam arsitektur dalam konteks Jawa. 


\section{KAJIAN LITERATUR}

Spiritual atau rohani secara umum dapat diartikan sebagai sifat yang berlawanan dengan fisik atau jasmani (Hutchins, 1952). Spiritualitas, berbeda dengan agama, mengakui keberadaan dan menjalin hubungan dengan yang transenden menurut dengan pengalaman individual tanpa kaitannya dengan dogma dan ritual (Van Niekerk, 2018). Spiritualitas tidak bersifat sekular, melainkan menghilangi batas antara yang sekular dan yang suci, yaitu cara menjalin hubungan dengan yang transenden, dan yang duniawi, yaitu jawaban terhadap pertanyaan mengenai sifat, tujuan dan makna kehidupan dan cara menjalaninya (RussoNetzer, 2018).

Dari catatan Maslow dan filsafat Timur, spiritualitas mengacu pada perilaku terhadap diri sendiri, orang lain, alam, dan alam semesta, sesuai dengan pandangan dunia dan kepercayaan masing-masing. Selain itu, benang merah spiritualitas adalah pelepasan ego. Aspek-aspek spiritualitas berupa kebiasaan (seperti doa, meditasi, atau ritual), kepercayaan (sikap terhadap yang transenden, ketuhanan, kematian dan cara mencapai keselamatan), dan pengalaman (seperti pengalaman gaib) (Russo-Netzer, 2018).

Untuk menciptakan jiwa setempat, Tadao Ando menggabungkan elemen abstrak dan real, dengan cara menggabungkan teknologi dan bahasa komposisional modern bersama ciri khas daerah dan kebiasaan lokal untuk menggalih sebuah makna dari bahasa tersebut. la berpendapat bahwa karena modernisme berupa bagian dari sejarah maka menjadi bagian dari konteks (Frampton, 1991).

Louis Kahn menjelaskan prinsip desainnya dengan menggunakan metafor Silence, yaitu yang tidak dapat diukur, dan Light, yaitu yang dapat diukur. Antara Silence dan Light terdapat Treasury of Shadows, yaitu dunia fisik. Seni berasal dari Order of the Shadow, antara ide dan kenyataan, antara Silence dan Light. Order menggambarkan sebuah keadaan melampaui kesatuan Silence dan Light. Konsep ini juga dikemukakan Lao Tzu, yang disebut sebagai Tao, dan Heidegger Being. Karena manusia terlalu sibuk dengan yang dapat diukur, dengan pengertian dan penyelidikan, kita telah melupakan Order, Tao atau Being.

Kahn menganggap arsitektur sebagai sebuah jalan spiritual. Tugas arsitek adalah untuk membuka jalur dari Silence ke dalam Light kemudian realisasikannya menjadi material. la memberikan metafora Institutions untuk menggambarkan tujuan sebuah bangunan, yang menyatakan bahwa sebuah bangunan itu memiliki jiwa yang hidup, yaitu bahwa sebuah bangunan memiliki keinginan untuk berada (desire to be). Keinginanan adalah kualitas dari dalam diri untuk berubah dari suatu keadaan ke keadaan yang lain. Misalnya rumah adalah untuk tempat tinggal, sekolah untuk belajar, etc.

la membedakan antara Form dan Design. Form disini berarti sebuah keinginan material atau bangunan untuk berada, dengan mempertanyakan "Apa keingingan bangunan ini?" Sedangakan Design adalah keinginan atau intuisi dari sang arsitek. Dalam membuat karya, harus ada Form dan Design. Pendekatan Kahn untuk mengetahui Form adalah dengan studi arsitektur kuno. Konsep keabadian Form serupa dengan konsep Jung yaitu ketidaksadaran kolektif dan arketipe dan pendekatan metode tipologi. Manifestasi dari Form tergantung pada konteks kultural dan waktu (Lobell, 2008).

Bagian berikut akan mengkaji tipologi arsitektur sepanjang sejarah Indonesia dan Jawa terhadap metode yang telah disebut di atas. Arsitektur tradisional yang telah dirancang menurut prototipe selalu terikat dengan makna simbolis (Lobell, 2008). Elemen transenden terjumpa pada rumah tradisional orang Jawa. Selain berfungsi sebagai teduhan, omah adalah tempat aktualisasi diri. Kajian terhadap rumah tinggal tradisional sama dengan kajian terhadap kehidupan budaya tersebut (Tjahjono, 1998).

Dari arsitektur tradisional Jawa agar dapat disimpulkan elemen-elemen yang dapat diterapkan dalam perancangan arsitektur spiritual, yaitu keselarasan antara mass dan void, alam dan manusia, cahaya dan bayangan, serta ruang dan waktu. 


\section{Mass dan Void}

Seni dan arsitektur berupa simbol dari kesadaran dan ketidaksadaran diri (Marcus, 1971). Karena banyak hal yang kita tidak dapat jelaskan, manusia menggunakan istilah simbolis untuk menjelaskan konsep yang tidak dapat dijelaskan (Jung, 1964). Manusia membutuhkan simbol karena kesadaran dan ketidaksadaran manusia terpisah. Celah tersebut semakin lebar akibat abad rasional (Wilber, 1979). Simbol dapat menjembatani antara kesadaran dan ketidaksadaran (May, 1960). Arsitektur, dalam upaya penyesuaian dengan konteks, berfungsi sebagai simbol yang menyampaikan arti yang tertanam dalam konteks budaya setempat (Trisno, Hanli, Kasimun, \& Lianto, 2019)

Dalam karyanya, Ando memisahkan bentuk dari fungsi untuk mencari makna sehingga akan ditemukan wujud aslinya. Bentuk sederhana dapat memperkaya ruang (Hien, 1998). Oleh sebab itu, ditelusuri bentuk awal dari tujuan bangunan.

Tempat-tempat natural seperti goa atau dibuat manusia dengan penggalian pertama dipisahkan dari ruang duniawi homogen (homogenous profane space) untuk teduhan dan ritual. Arsitektur goa pertama digunakan untuk upacara pemakaman yang kemudian direplikasi sebagai penengah yang mati dan yang hidup (Barrie, 2010). Pada zaman megalitikum terdapat dolmen yang didirikan untuk tujuan yang sama.

Bentuk goa mulai berubah menjadi gundukan, yang ditemukan pada arsitektur Budha berwujud stupa. Stupa awalnya digunakan untuk menyimpan peninggalan Budha dan kemudian menjadi kuil Hindu yang digunakan untuk pemujaan dan meditasi (Curl, 2000). Setelah agama Hindu dan Budha datang ke Indonesia, stupa dan kuil Hindu berkembang menjadi candi. Digabungkan dengan kepercayaan Nusantara, candi menjadi tempat kediaman para dewa dan melambangkan Gunung Meru, tempat kediaman para dewa yang sebenarnya. Bentuk denah melambangkan mandala dan tampaknya melambangkan tiga ranah spiritual dalam kosmologi Budha, yaitu bhurloka, bhuvarloka, and svarloka (Soekmono, 1995). Mandala sendiri adalah gambaran dunia (imago mundi) dan titik tengahnya adalah poros dunia (axis mundi), yaitu tempat pertemuan antara langit dan bumi dan 4 mata angin. Gubahan berawal dari gundukan setengah bulat kemudian menjadi punden berundak, mungkin untuk kepraktisan konstruksi.

Candi atau kuil Hindu pada umumnya memiliki simbolisme goa dan gunung. Gunung berupa ikatan antara bumi, tempat manusia yang duniawi, dan langit, asal dewa yang suci. Kepercayaan masyarakat nusantara adalah untuk mengundang dewa turun pada tempat persembahan, bukan untuk persembahan naik ke langit, sehingga gunung atau arsitektur pemujaan adalah sebagai tangga turunnya dewa (Domenig, 2014).

Rumah tinggal tradisional Jawa dianggap sebagai tempat dimana jagad cilik (microcosmos), yaitu manusia, dan jagad gede (macrocosmos), yaitu alam semesta, bertemu. Sama seperti mandala, omah adalah poros dunia dan gambaran dunia bagi orang Jawa (Eliade, 1959) (Tjahjono, 1989).

Pendopo, dengan bentuk yang berasal dari rumah adat dan konstruksi Joglo, berfungsi sebagai masjid saat Islam pertama datang (Budi, 2005). Pada saat itu, atap pendopo juga melambangkan gunung, namun bukan perubahan bentuk tetapi pembaharuan lambang. Fungsi pendopo berasal dari fungsi mandapa pada arsitektur Hindu, yaitu untuk berkumpul. Bentuk rumah adat disebabkan oleh kepraktisan dan teknik konstruksi. Seperti pada arsitektur tradisional Cina, tidak ada perbedaan antara bentuk dan fungsi. Bentuk yang sama dapat digunakan untuk berbagai fungsi, mulai dari tempat tinggal hingga tempat berkumpul. Secara keseluruhan, tipologi rumah ibadah tradisional memiliki simbolisme dan fleksibilitas.

Setelah itu masjid mulai mengadopsi gaya Bizantium, yang awalnya berfungsi sebagai gereja kemudian beralih fungsi menjadi masjid setelah jajahan Ottoman. Gereja Bizantium, menurut Eliade, melambangkan langit dan surga, dengan empat mata angin dan kubahnya (Eliade, 1959). Tempat di bawah kubah adalah temapt dimana Tuhan menyatakan diriNya (Davies, 1952). 


\section{Alam dan Manusia}

Rancangan arsitektur rumah tradisional muncul dari penyesuaian dengan alam dan iklim (Prijotomo, 2010). Keselarasan dengan alam semesta dijaga dengan menghormati tapak dan alam sekitar (Tjahjono, 1989).

Ando mengatakan ruang selalu berubah dalam hubungannya dengan alam (Baek, 2009). Karya Ando yang terletak di dalam kota menanggapi lingkungan yang kacau dengan cara menutup ke dalam dan mengelilingi halaman yang ditutup dinding beton, seperti pada Kidosaki House. Yang dibangun di tengah tengah alam, Ando memadukan bangunan dengan alam dengan cara membukanya terhadap alam seperti pada Children's Museum, Hyogo, atau menggali ke dalam seperti pada Forest of Tombs Museum, Kumamoto dan Chikatsu-Asuka Historical Museum, Osaka (Frampton, 1991).

Alam juga dapat dimasukkan ke dalam bangunan dengan bukaan-bukaan tanpa kaca. Kata Ando, "Saya percaya arsitektur tidak harus berbicara banyak. Dia harus diam dan biarkan alam masuk dalm bentuk cahaya matahari dan angin." Dalam mempertanyakan hubungan arsitektur dan alam tidak bisa lepas dengan hubungannya dengan waktu (Baek, 2009). Dari arah angin, kemiringan sinar matahari, tetesan air hujan, bahkan siklus bulan menandakan pergerakan waktu. Alam yang dimasukkan ke dalam bangunan yang dibuat manusia dirasakan oleh pengamat yaitu manusia.

\section{Cahaya dan Bayangan}

Cahaya digunakan sebagai perantara untuk memunculkan kehidupan dan jiwa ke dalam bangunan (Baek, 2009). Pada rumah tradisional Jawa, rumah tersusun berdasarkan hierarki cahaya, mulai dari yang paling terang hingga yang paling gelap.

Diambil kutipan dari Louis Kahn (Lobell, 2008):

'Segala material di alam, dari gunung, sungai, udara dan manusia, semua terbuat dari cahaya yang dihabiskan, dan gumpalan massa yang disebut sebagai material menghasilkan bayangan, dan bayangan adalah milik cahaya... Seperti sebuah api yang berkobar dan menetap pada material dan habis, begitu pula cahaya.'

Kahn sadar bahwa material mulai ketika cahaya berhenti. Cahaya sangat penting bagi arsitektur, ia adalah pemapar arsitektur. Arsitektur kuno menggunakan dinding tebal dengan bukaan yang merefleksikan cahaya dari sisinya, kemudian membentuk dan menyaring cahaya ketika masuk ke dalam ruangan. Arsitektur modern, dengan dinding tipis dan penggunaan kaca tidak dapat menyediakan modulasi cahaya demikian. Kahn berusaha untuk mengembalikan modulasi cahaya yang terdapat pada arsitektur kuno sebelum cahaya masuk ke dalam ruangan (Lobell, 2008). Untuk menghasilkan suasana spiritual, dinding harus lebih besar dari bukaan (Trisno \& Lianto, 2018).

Kahn juga ingin mengembalikan kehormatan terhadap material yang ada pada arsitektur kuno (Lobell, 2008). Begitu juga dengan Ando, mereka menggunakan material mentah tanpa ditutup-tutupi untuk menghormati 'keinginan' material tersebut. Beton banyak digunakan dalam bangunan mereka karena tidak berwarna sehingga, menjadi kanvas yang tepat untuk melukis cahaya, bayangan, air, dan alam.

\section{Ruang dan Waktu}

Rumah tinggal bagi orang Jawa adalah tempat atau tatanan tempat, konsep ruang geometris tidak relevan dalam pengertian rumah tinggal Jawa. Demikianlah pengertian ruang dalam rumah tinggal Jawa ini mencakup aspek tempat, waktu dan ritual (Kartono, 2005). Ando juga mengatakan bahwa arsitektur spiritual perlu memasukkan gagasan waktu sebagai produk daerah dan sejarah setempat (Baek, 2009).

Arsitektur dirasakan melalui perjalanan sesuai dengan urutan spasial menggunakan indra manusia, terutama penglihatan dan pergerakan. Pergerakan, urutan spasial, dan waktu menciptakan elemen keempat dalam persepsi dunia kita (Barrie, 1996). Pada arsitektur sakral, 
biasanya terdapat narasi simbolik yang sesuai dengan ritual untuk mencapai koneksi dengan yang ilahi. Selalu ada sebuah jalur antara yang duniawi dan yang suci, sebagai perantara ruang luar dan dalam (Barrie, 2010).

Rumah tradisional Jawa menggunakan jalur linear sesuai dengan hierarki cahaya. Teras dan pagar sebagai perantara dunia luar dengan dalam. Pendopo adalah tempat berkumpulnya tamu, kemudian pringgitan adalah tempat pertunjukan wayang untuk kerabat dekat. Dalem adalah tempat tinggalnya keluarga, dan merupakan tempat paling sakral, terutama pada senthong tengah, yang dulunya dikosongkan untuk kediaman dewa. Terdapat bangunan tambahan di samping atau belakang rumah, yaitu gandok yang berfungsi sebagai toilet dan dapur.

Pada arsitektur tradisional Hindu-Budha, banyak digunakan jalur radial dan keliling yang sesuai dengan bentuk mandala. Jalur radial dimana suatu kotak atau lingkaran dibagi menjadi empat melambangkan empat penjuru dunia, dan titik temu di tengah adalah axis mundi. Jalur keliling, seperti pada Borobudur, melambangkan sebuah perjalanan yang takzim dan bertahap menuju keilahian. Seorang berjalan mengelilingi pusat suci, mendekat namun tidak terlalu dekat, dan terkadang pusat tidak dapat dicapai (Barrie, 2010).

\section{METODOLOGI}

Metodologi yang didasari Tadao Ando dan Louis Kahn mencoba menggabungkan elemen abstrak dan real ke dalam arsitekturnya. Untuk merealisasikan keabstrakan menjadi bangunan nyata, keduanya menggunakan bahasa modern sebagai simbol untuk menceritakan ide abstrak yang abadi melalui penggalian tipologi. Mereka mencari tipe melalui kajian terhadap bangunan tradisional. Tipe yang didapatkan diterjemahkan menjadi model, yaitu bentuk fisik, sesuai dengan konteks dan menggunakan komposisi geometris dan skala modern, yaitu untuk menentukan tinggi lantai bangunan, besar bukaan, dll.

Maka dari itu, diselidiki arsitektur tradisional Jawa agar dapat disimpulkan elemen-elemen yang dapat diterapkan dalam perancangan arsitektur spiritual. Elemen-elemen tersebut kemudian diuji terhadap studi kasus Pusat Spiritual yang terletak di Kedoya, Jakarta Barat. Metode yang diperlukan untuk menimbulkan suasana spiritual adalah keselarasan antara mass dan void, alam dan manusia, cahaya dan bayangan, serta ruang dan waktu.

\section{DISKUSI DAN HASIL}

Pusat Spiritual terletak di Kedoya Selatan, tepatnya di seberang stasiun Metro TV, dengan rencana hutan reklamasi di belakangnya, dan Metropark Residence di sisi selatannya. Hutan reklamasi saat ini tidak dapat diakses publik. Jalanan depan tapak dipenuhi kios dan parkir liar yang menyediakan makanan murah dan parkir gratis untuk pegawai Metro TV dan penghuni apartemen. Maka dari itu, bangunan berpotensi untuk menjadi pusat aktivitas yang mewadahi kios dan menyediakan foodcourt dan juga sebagai pintu masuk ke dalam hutan.

Pusat Spiritual berfungsi sebagai tempat berkumpulnya komunitas spiritual dan menyediakan wadah untuk memenuhi kebutuhan spiritual masing-masing individu dalam satu tempat. Dalam memenuhi kebutuhan spiritual, disediakan program untuk kebutuhan yang bersifat 'sakral' seperti ruang kontemplasi untuk introspeksi diri, meditasi, yoga, dll., dan juga yang bersifat 'duniawi' seperti forum untuk dialog interaktif, diskusi, konseling, dll.

Seperti yang disimpulkan di bagian sebelumnya, keselarasan antara mass dan void, alam dan manusia, cahaya dan bayangan, serta ruang dan waktu dapat diterapkan dalam desain pusat spiritual untuk mewujudkan elemen transenden dalam ruang monoton.

\section{a. Mass dan Void}

Gubahan menggunakan simbol yang diambil dari nilai budaya melalui studi arsitektur nusantara kuno, sehingga tertanam dalam ketidaksadaran kolektif masyarakat. Bentuk terpisah dari fungsi interior, dimana fungsi mengikuti bentuk. 
Bentuk gubahan terdiri dari kotak yang sebagian tertanam dalam tanah dengan void di tengah. Denah berbentuk seperti mandala dengan void yang berbentuk kubah. Mandala adalah axis mundi dan imago mundi, dengan titik di tengah sebagai titik pertemuan antara langit dan bumi dimana terbuka hubungan antara manusia dengan yang ilahi. Seperti bibit tumbuhan yang sedang berkecambah, massa yang sebagian keluar dari tanah melambangkan iman dan pertumbuhan spiritual.
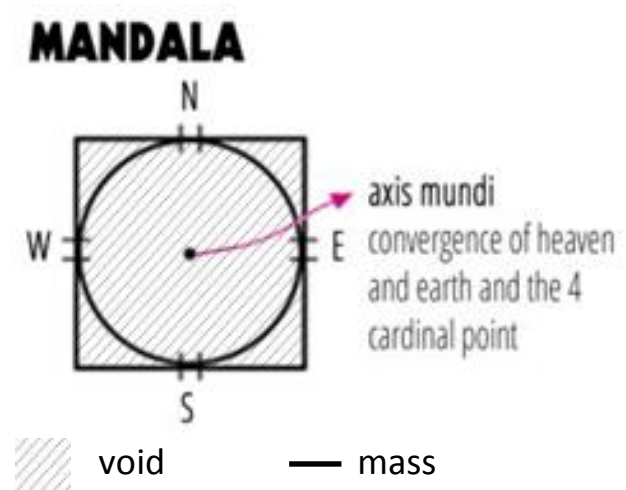

\section{DOME}

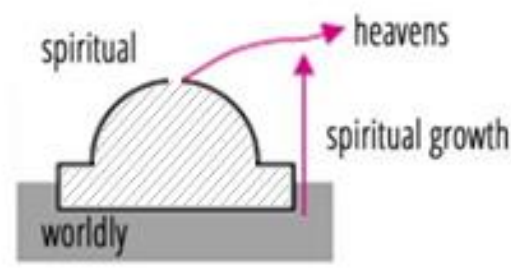

Gambar 1. Simbolisme berdasarkan tipologi yang memengaruhi bawa sadar masyarakat Sumber: Penulis, 2019

\section{b. Alam dan Manusia}

Bangunan menanggapi lingkungannya dengan menjembatani kekacauan kota dan kekacauan alam dengan mencipatakan sebuah komposisi dinding, bukaan, dan kolom yang terlihat seperti reruntuhan. Sedangkan interior diterlindung dari kekacauan dengan cara mengarah ke dalam dan dilindungi oleh sejajaran kios dan terdiri dari komposisi geometris yang sederhana. Halaman belakang yang miring terbuka terhadap alam.

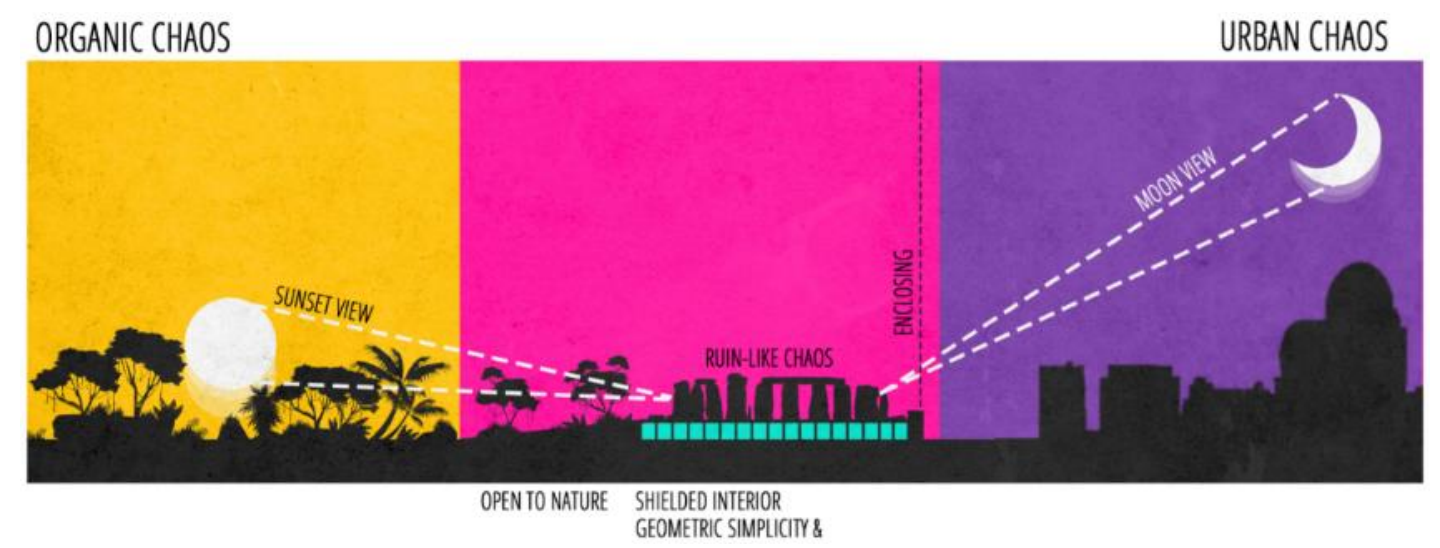

Gambar 2. Tanggapan bangunan \& manusia terhadap lingkungan

Sumber: Penulis, 2019

Hubungan alam dengan bangunan tidak lepas kaitannya dengan waktu. Bangunan ini mencoba menangkap alam, baik dari angin, cahaya, air dan bulan ke dalamnya sehingga di dalam interior pun elemen waktu dapat terasa. Di lantai paling atas, kolom di sisi barat berfungsi sebagai jam yang menggunakan bayangan matahari untuk mengetahui pergantian bulan, bukaan di sisi barat juga berfungsi sebagai bingkai bulan sabit, sedangkan bukaan-bukaan di sisi timur membingkai bulan purnama. 


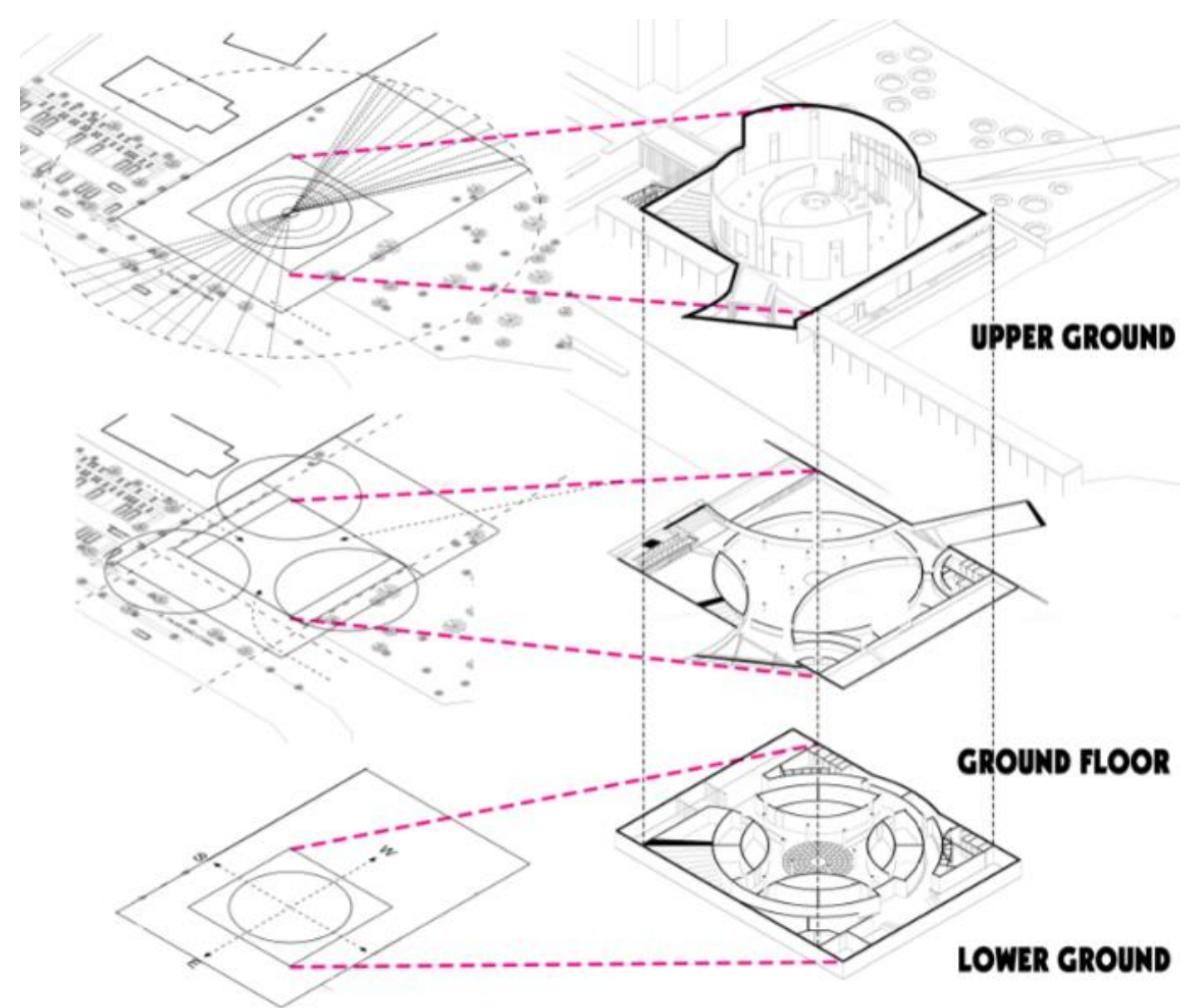

Gambar 3. Skema desain pusat spiritual

Sumber: Penulis, 2019

Lantai dasar dan bawah tanah tertanam agar lebih sedikit luas permukaan yang terpapar matahari langsung dan panas kota, sebagai penyangga suara, dan juga sebagai penyaring cahaya untuk menciptakan atmosfer spiritual. Halaman yang tertanam di lantai bawah, bukaan pada titik tengah kubah, dan kolam kaca pada lantai dasar memungkinkan ventilasi alami dan sinar matahari untuk mencapai hingga lantai bawah bangunan.

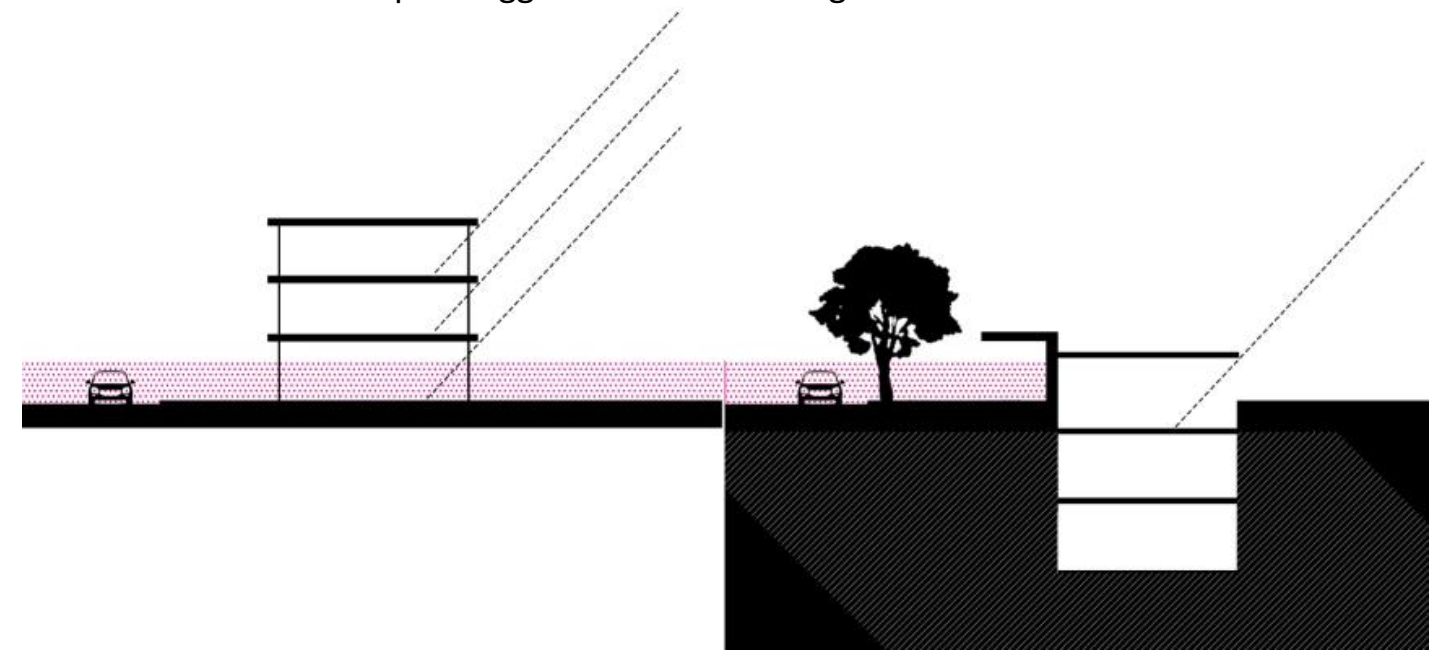

Gambar 4. Bangunan pada umumnya (kiri) dibandingkan dengan bangunan bawah tanah (kanan)

Sumber: Penulis, 2019 

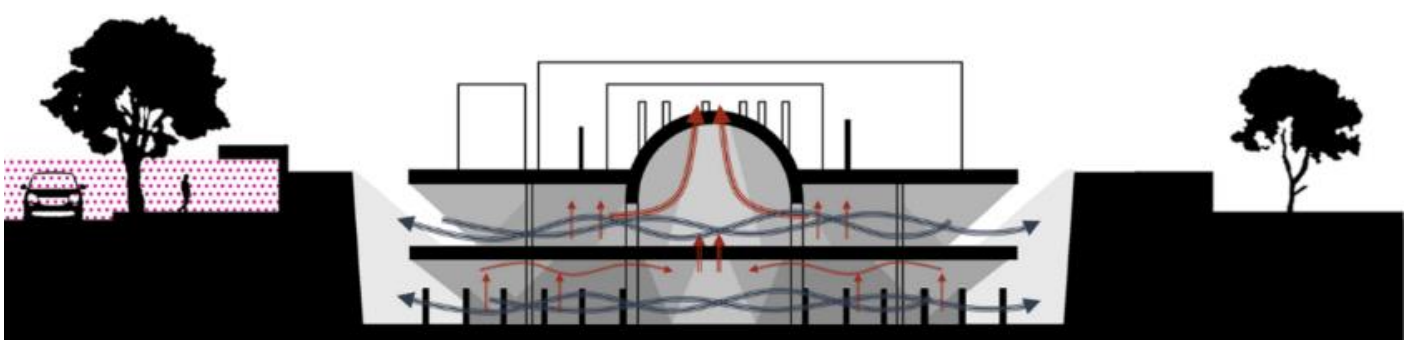

Gambar 5. Potongan diagramatik ventilasi alami

Sumber: Penulis, 2019

\section{c. Cahaya dan Bayangan}

Cahaya adalah simbol keilahian, ketika manusia menerima pencerahan, ia menjadi lebih dekat dengan yang ilahi. Seperti pada rumah tradisional Jawa, ruang ditata berdasarkan hierarki cahaya. Cahaya erat kaitannya dengan material, seperti yang dikatakan Kahn, material mulai ketika cahaya berhenti. Rancangan bangunan mencoba untuk menyaring cahaya dengan material padat modern yaitu beton yang berfungsi sebagai struktur dan elemen arsitektural, sehingga kekokohan dan kesan monumental pada arsitektur candi dan masjid jaman dahulu tercerminkan. Beton digunakan sebagai kanvas untuk melukis cahaya, bayangan, air dan alam. Diusahakan untuk menggunakan material mentah tanpa ditutup-tutupi agar 'keinginan' material terpenuhi.

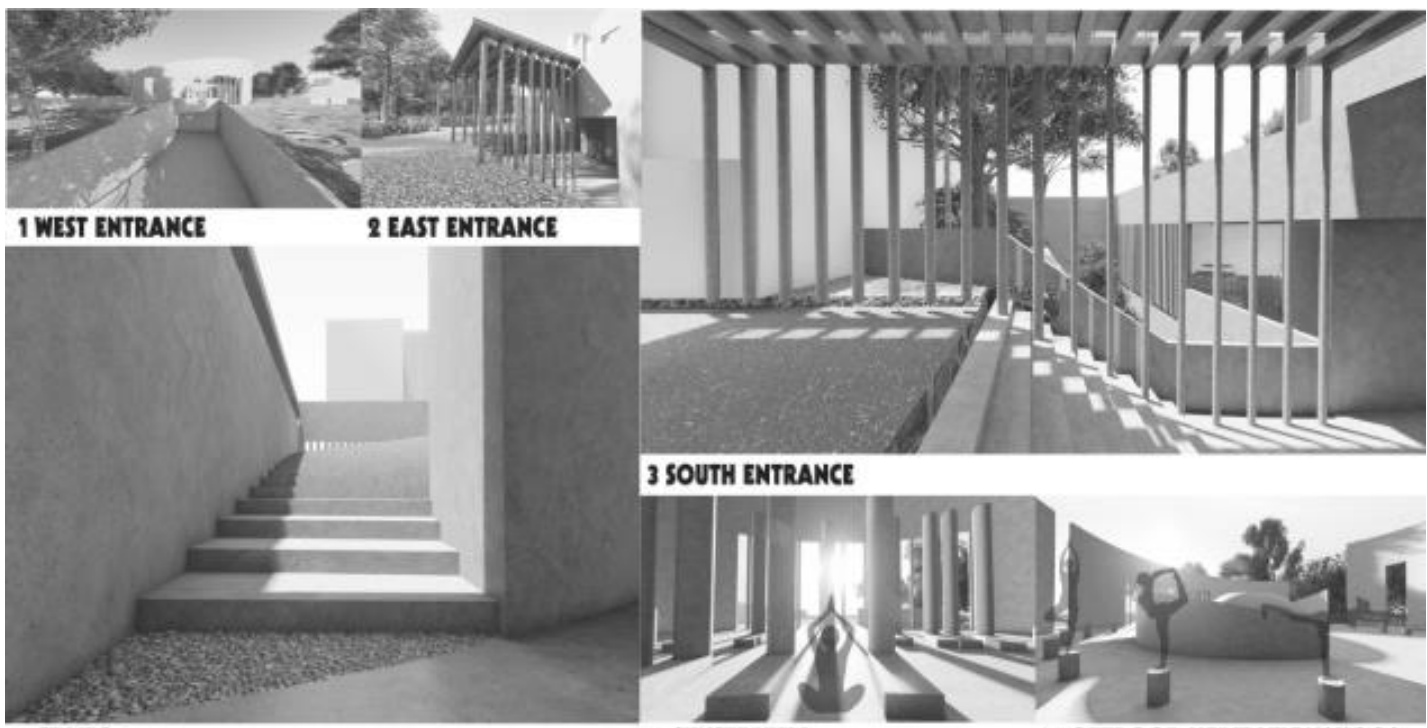

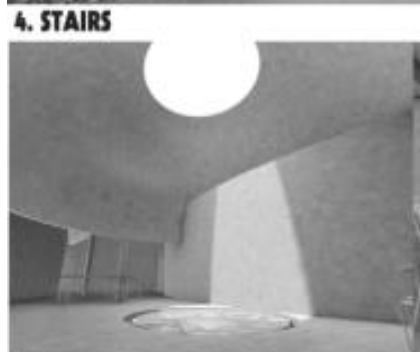

7. LOBBY

\section{SUNSET VIEW}

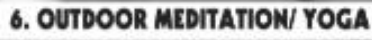

Gambar 6. Modulasi cahaya sesuai dengan tingkat kesakralan (bagian 1)

Sumber: Penulis, 2019 


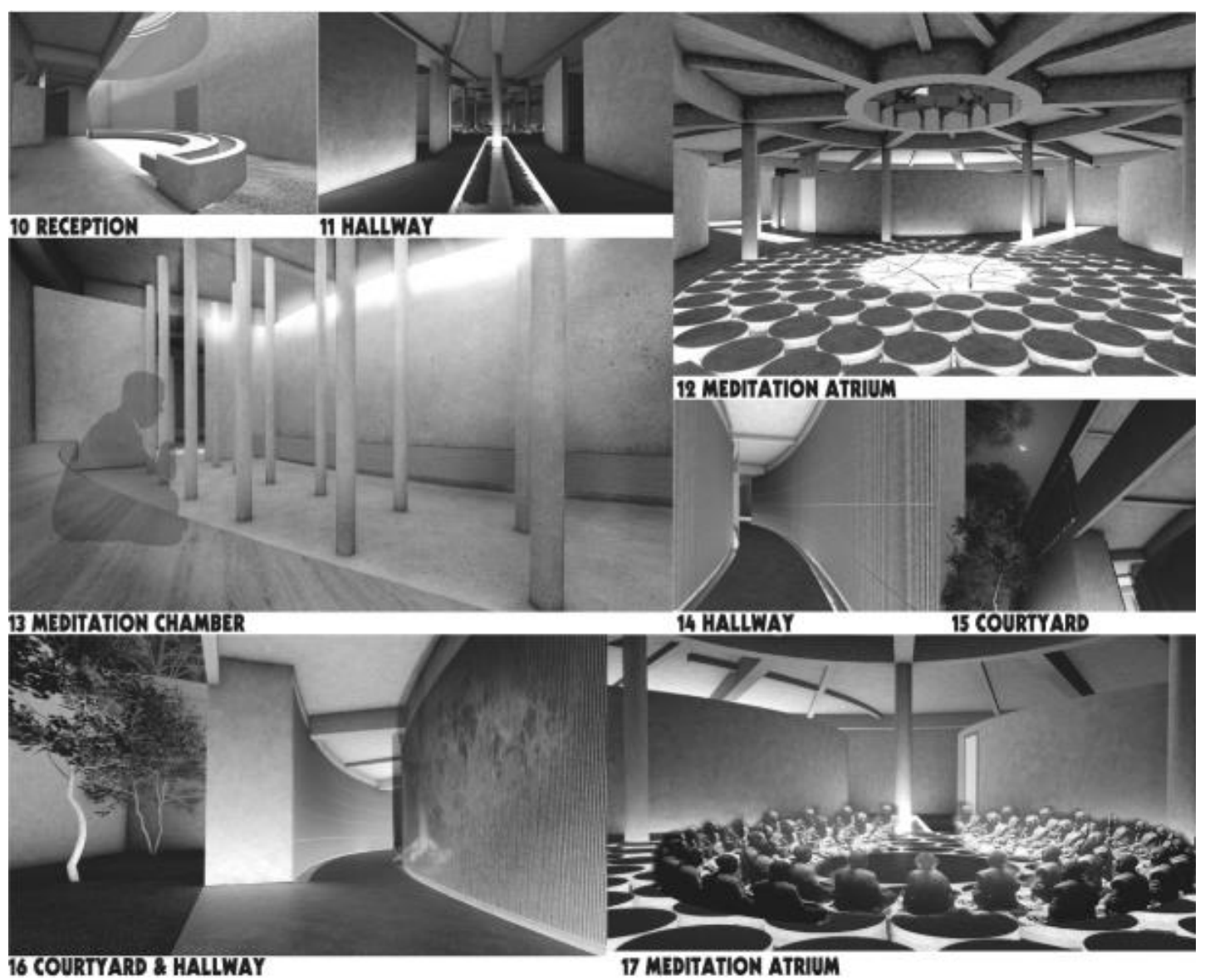

Gambar 7. Modulasi cahaya sesuai dengan tingkat kesakralan (bagian 2) Sumber: Penulis, 2019

\section{d.Ruang dan Waktu}

Sebuah perjalanan menuju pencerahan diceritakan dalam urutan spasial yang mengikuti rumah tradisional Jawa secara narasi, namun secara spasial mengikuti jalur radial dan keliling yang sesuai dengan bentuk gubahan.

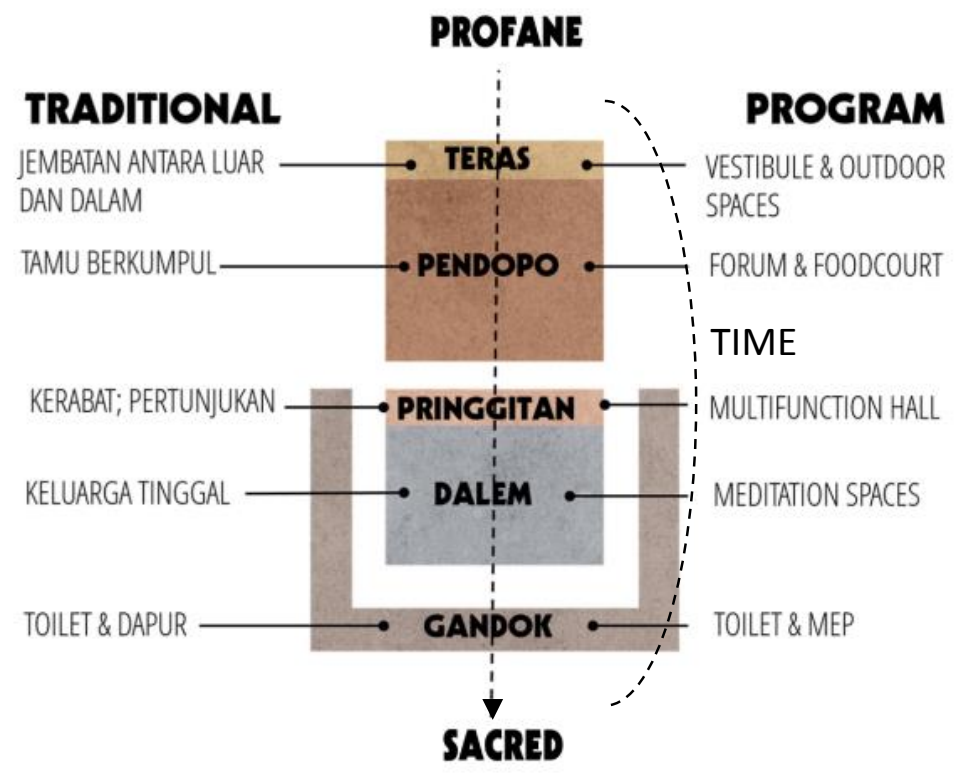

Gambar 8. Urutan spasial berupa narasi simbolik yang sesuai dengan ritual Sumber: Penulis, 2019 
Perjalanan dimulai dari pintu masuk yang berupa sambungan dari jalur pedestrian menuju titik tersebut, yang berfungsi sebagai perantara ranah luar dengan dalam. Kemudian ada ruang perantara yang sambung dengan fungsi servis seperti toilet, lift, dan tangga. Terdapat dua bukaan di kanan dan kiri menuju pendopo dengan fungsi sebagai forum rangkap foodcourt yang juga terdapat pada lantai atas yang dicapai melalui tangga. Pendopo diterangi bukaan pada kubah di tengah dan dari void di sisi selatan bangunan, dengan cahaya yang disaring menggunakan kisi-kisi. Pringgitan, yang berupa balai multifungsi, diakses melalui pendopo. Pringgitan diterangi satu bukaan di belakang panggung sehingga pembiacara atau pemain di panggung terlihat sebagai bayangan seperti pada wayang dan untuk menambah kesan spiritual pada pembicara. Dalem berfungsi sebagai tempat kontemplasi, untuk introspeksi diri dan menjalin hubungan dengan yang transenden. Dalem yang berada pada lantai bawah diterangi hanya dari kolam yang berada di lantai dasar dan cahaya pada void, namun disaring juga dengan dinding pada lingkaran dalam. Oleh sebab itu, penerangan pada dalem remangremang, terutama untuk meningkatkan konsentrasi dan membuat kesan tenang dan sunyi.

\section{KESIMPULAN DAN SARAN Kesimpulan}

Spiritualitas terdiri dari elemen suci dan duniawi, sehingga arsitektur yang spiritual menerjemahkan yang abstrak ke dalam yang real. Maka dari itu diperlukan tipologi sesuai dengan konteks untuk mengetahui tipe yang bersifat abstrak dan mewujudkannya menjadi bangunan nyata. Keselarasan antara mass dan void, alam dan manusia, cahaya dan bayangan, serta ruang dan waktu dapat mewujudkan elemen transenden dalam ruang monoton. Sehingga disimpulkan dan ditemukan bahwa kesatuan dalam dualitas adalah prinsip penting dalam proses perancangan arsitektur spiritual.

\section{Saran}

Untuk selanjutnya, disarankan untuk meneliti lebih lanjut cara mewujudkan arsitektur spiritual menggunakan komposisi dan teknik modern.

\section{REFERENSI}

Baek, J. (2009). Nothingness: Tadao Ando's Christian Sacred Space. New York: Routledge.

Barrie, T. (1996). Spiritual Path, Sacred Place. Myth, Ritual and Meaning in Architecture. Boulder: Shambhala.

Barrie, T. (2010). The Sacred in Between. The Mediating Roles of Architecture. New York: Routledge.

Budi, B. S. (2005). A Study on History and Development of the Javanese Mosque Part II. AlJ.

Curl, J. S. (2000). A Dictionary of Architecture and Landscape Architecture. Oxford: Oxford University Press.

Davies, J. G. (1952). The Origin and Development of Early Christian Church Architecture. London: SCM Press.

Domenig, G. (2014). Religion and Architecture in Premodern Indonesia. Studies in Spatial Anthropology. Leiden: Brill.

Eliade, M. (1959). The Sacred and the Profane. New York: Harvest Book.

Frampton, K. (1991). Tadao Ando. New York: The Museum of Modern Art.

Hien, P. (1998). Abstraction and Transcendence: Nature, Shintai, and Geometry in the

Architecture of Tadao Ando. Cincinnati: University of Cincinnati.

Jung, C. (1964). Man and His Symbols. New York: Doubleday.

Kartono, J. L. (2005). KONSEP RUANG TRADISIONAL JAWA DALAM KONTEKS BUDAYA. Dimensi Interior, 3(2), 124-136. 
Lobell, J. (2008). Between Silence and Light: Spirit in the Architecture of Louis I. Kahn (2nd ed.). Boulder: Shambhala.

Marcus, C. C. (1971). The House as a Symbol of Self. Berkeley: University of California.

May, R. (1960). Symbolism in Religion and Literature. New York: George Braziller.

Prijotomo, J. (2010). Arsitektur Nusantara: Arsitektur Naungan, Bukan Lindungan. Ternate: Universitas Khairun.

Soekmono, R. (1995). The Javanese Candi: Function and Meaning (Vol 17 ed.). Leiden: E.J. BRILL.

Tjahjono, G. (1989). Cosmos, Center and Duality in Javanese Architectural Tradition: The Symbolic dimensions of house shapes in Kotagede and surroundings. Berkeley: University of California.

Tjahjono, G. (1998). Architecture. Indonesian Heritage. Singapore: Archipelago Press.

Trisno, R., \& Lianto, F. (2018). The Meaning of Natural Lighting on Altar Case Study: Cathedral Church and the Church of the Light. IJCIET, 9(12).

Trisno, R., Hanli, N., Kasimun, P. R., \& Lianto, F. (2019). THE MEANING OF MEANS: SEMIOLOGY IN ARCHITECTURE CASE STUDY: VILLA SAVOYE. IJCIET, 653-660.

Van Niekerk, B. (2018). Religion and spirituality: What are the fundemental differences? HTS Teologiese Studies/Theological Studies.

Wilber, K. (1979). No Boundary. Boston: Shambhala. 
